LUIZ COSTA LIMA

é professor de Literatura Comparada da

Universidade do Rio de Janeiro e da PUC-Rio e autor de, entre outros, Ignota. A Construção de Os Sertões (Civilização Brasileira).

\title{
Sobre Bandeira e Cabral
}

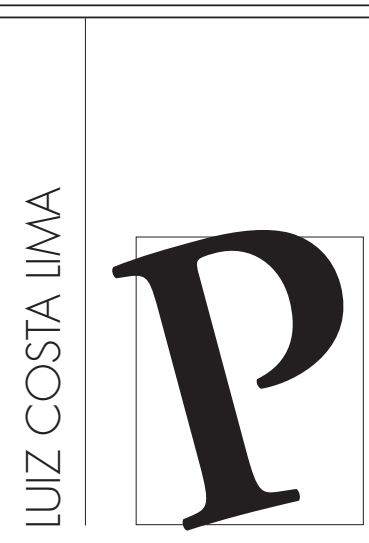

rocuraremos demonstrar que os modelos poéticos de Manuel Bandeira e João Cabral de Melo Neto são bastante distintos, sem que sejam antagônicos. Isso significa que, discrepantes, admitem um traço de semelhança. Mas para fazêlo antes precisamos vir à própria expressão "modelo poético": ela é vaga e, portanto, sujeita a equívocos. Seja este pois nosso primeiro esclarecimento: ao contrário do que sucede na indústria, "modelo" aqui não significa a reprodução a priori indeterminada de um mesmo padrão mas, ao contrário, uma disposição fundamental, uma protoforma que abriga variações, estas simmúltiplas. Tentaremos concretizar essas protoformas por um número bastante reduzido de textos. Se conseguirmos, teremos mostrado que, de Bandeira a Cabral, a estruturação da linguagem poética brasileira se enri-
Texto apresentado no seminário "Cabral-Bandeira-Drummond", na Fundação Casa de Rui Barbosa $(\mathbb{R}) \mid$, em mesa-redonda de que também participaram Augusto Massi e Júlio Castañon Guimarães, em 23 de março de 2001 
queceu com variedades e alternativas. Antes de fazê-lo, dois outros esclarecimentos são necessários: a) o mais importante está em declarar que tal mudança na estruturação implica a modificação drástica do eixo de composição do poema, istoé, que ele passa a utilizar sua matéria-prima, as cenas de referência, de maneira incomparável; b) o segundo esclarecimento responde a uma crítica que tem acompanhado o Lira $e$ Antilira, tanto em sua primeira edição (1968) como na segunda (1995). O livro, que tinha por meta analisar a poesia brasileira, a partir do modernismo, em suas figuras mais marcantes, de Bandeira a Cabral, veio a ser criticado por praticar um evolucionismo que podemos dizer retardado, que teria Bandeira por termo inicial e encontraria seu ápice em Cabral. A crítica partia pois do suposto que o Lira e Antilira se conformava a uma concepção linear de tempo, em que o posterior haveria de ser mais complexo e melhor do que o termo precedente.

Não pretendo dizer que meus críticos eram arbitrários, mesmo porque nada ali se dizia contra a suposição que explorariam. Além do mais, como razões de economia editorial tinham reduzido a parte dedicada a Bandeira a dois parágrafos da "Introdução" e o capítulo sobre Cabral era o mais extenso, o leitor podia subentender que se afirmava a absoluta superioridade do autor de "Uma Faca só Lâmina". Outros motivos encaminhavam na mesma direção: as pessoas ligadas ao meio literário sabiam que, por um lado, Cabral servia de respaldo para a experiência da poesia concreta e, por outro, de minha admiração e amizade com os irmãos Campos. A “evolução” que então viam praticada no livro, em suma, pareciathes uma justificativa indireta do concretismo. A razão mais importante, porém, ocorria por culpa minha: embora o conceito de "contemporaneidade do nãocontemporâneo" (Ungleichzeitigkeit) tivesse sido elaborado em 1932 e circulasse em livro desde 1935, no momento da feitura do Lira e Antilira, eu simplesmente o desconhecia. Como ele é fundamental para que se entendam as conseqüências da diversi- dade dos modelos bandeiriano e cabralino, traduzo a abertura do ensaio em que seu autor, Ernst Bloch, explicava o conceito. Dizia ele então: "Nem todos estão no mesmoagora. Aí se encontram apenas externamente, de modo que são hoje de ser vistos. Mas não é por isso que vivem no mesmo tempo que os outros" (E. Bloch, 1935, p. 104). A passagem é bastante clara para que seja ainda esclarecida. Apenas se acrescente: afirmar a contemporaneidade do não-contemporâneo supõe que o tempo, em vez de tomado como um fio que se desenrola, compreende o descompasso, a fratura, a irregularidade; o heterogêneo. Em nosso caso, isso significa dizer que, se considerarmos, no momento de agora, o tempo pós-cabralino, é de se prever a contemporaneidade também de uma poesia de estruturação antes bandeiriana ou até seguidora doutras estruturações. Cada uma delas provocará ramificações ou estratificações diversas, sem que tal marcação de origem condicione seu maior ou menor valor.

Esclarecimentos feitos, venhamos ao objeto de escolha: mostrar a diferença das protoformas bandeiriana e cabralina.

Tanto de Bandeira como de Cabral, tomaremos como peças básicas poemas conhecidos, porém não dos mais famosos. No primeiro caso, "Meninos Carvoeiros", pertencente ao Ritmo Dissoluto (1921), publicado na primeira reunião de sua obra, $P o-$ esias (1924).

"Os meninos carvoeiros

Passam a caminho da cidade. - Eh, carvoero!

E vão tocando os animais com [um relho enorme.

Os burros são magrinhos [e velhos.

Cada um leva seis sacos de [carvão de lenha.

A aniagem é toda remendada. Os carvões caem.

(Pela boca da noite vem uma [velhinha que os recolhe, dobrando-se com um gemido). 
- Eh, carvoero!

Só mesmo estas crianças raquíticas

Vão bem com estes burrinhos

[descadeirados.

A madrugada ingênua parece feita para

[eles...

Pequenina, ingênua miséria!

Adoráveis carvoeirinhos que trabalhais

[como se brincásseis!

- Eh, carvoero!

Quando voltam, vêm mordendo num pão

[encarvoado,

Encarapitados nas alimárias,

Apostando corrida,

Dançando, bamboleando nas cangalhas

[como espantalhos desamparados".

A flagrante irregularidade métrica fonte, contudo, de um ritmo singular e não só dissoluto -, as formas diminutivas, a grafia segundo a pronúncia oral do refrão exclamativo são sinais evidentes da adoção do coloquial modernista, que o poeta só não segue pelo uso eventual da segunda pessoa do plural. A continuação do exame das marcas verbais revela contudo um traço curioso: embora todas as formas verbais estejam no presente do indicativo, no presente progressivo ou em reduzidas gerundiais transformáveis em presente do indicativo, com ênfase nos versos finais "apostando corrida”, “dançando, bamboleando" -, que ressaltam o efeito de cena presente, esse presente gramatical não tem nenhuma relação com o presente referencial. Ao contrário, a cena em que estão os verbos no presente antes aparece como uma cena da memória. Os meninos carvoeiros passam como se o tempo houvesse cessado, para que sobre seu vazio melhor se destacassem suas tristes figuras sujas. E o refrão exclamativo se encrava como uma voz anônima, que, em sua coloquialidade, adensa de afeto o tempo congelado. Pois é bem a afetividade que prepondera, ocupando o lugar do que, nas artes plásticas, desde o Renascimento até o neoclássico, fora reservado ao tratamento perspectivístico. Assim, embora sejam assinalados um antes e um depois - “Os meninos carvoeiros / passam a caminho da cidade", "Quando voltam [...]" - não há, na verdade, um antes e um depois porque, vazio de presente, o tempo olha para trás. A característica pois a acentuar consiste na conversão da expressão temporal em impressão afetiva. Com o que os elementos da cena externa se imobilizam e se transformam em agentes de emoção.

A essa conversão acrescenta-se outro traço: a carga emocional que domina o poema não decorre de alguma exploração do psicológico. Não há exploração de um eu mas uma afetividade que, unânime, domina toda a cena. Como dizia Mário de Andrade, “o poeta se generaliza”, "por mais pessoais que sejam assuntos e detalhes, mais o poeta se despersonaliza" (M. Andrade, 1931, p. 30). A despersonalização, como veremos, é o traço que emigra até Cabral. A "poesia do cotidiano", que Bandeira viria a dizer haver aprendido a apreciar em Blaise Cendrars (M. Bandeira, 1957), conduz o poeta a um cotidiano em que o tempo presente se refugia em um instante da memória, esvaziando-se junto com a pessoalidade. Sob o eu que se dissolve, a afetividade impregna os versos simples, para que, sob a forma de emoção, o leitor a reacenda.

Ainda tenhamos umas mínimas corroborações. A subordinação do presente a uma cena guardada na memória é bastante óbvia no belíssimo "Profundamente" (em Libertinagem, 1930). O presente apenas se anuncia para dizer-se que não está mais aqui: "Hoje já não ouço mais as vozes daquele tempo". Onde estão as vozes dos que amei, onde aqueles que hoje apenas nomeio? O tempo presente vaza para o subsolo. O poema propriamente dito só contém uma superfície: a que o passado instila.

As variantes da protoforma são múltiplas e seria impossível catalogá-las. Consideremos apenas a comprovação doutra variante: "Momento num Café" (em Estrela da Manhã, 1936). "Quando o enterro passou", todos reverenciaram o morto automaticamente, exceto um cuja singularidade admitia a afirmação no presente: "Este sabia que a vida é uma agitação feroz e sem finalidade / Que a vida é traição". O pre- 
sente se mostra pleno apenas quando se trata de indicar o caráter escorregadio, o passo em falso provocado pela matéria que compõe a vida. O afeto sobre o qual será engendrada a emoção que o poema provoca responde a esse saber. É mesmo por se mostrar traidora a vida que o tempo presente se esvazia, foge do presente, concentrando-se em instantes privilegiados, em que o que fora tão-só privado e pessoal se socializa.

Em síntese, o esquema axial ou a protoforma de Bandeira supõe o esvaziamento do presente, concentrando-se o tempo em instante raro do passado, que se revestirá de um afeto impessoalizado que propiciará a socialização do emotivo.

Pequeno parêntese: aqueles que conheçam a análise que Davi Arrigucci dedicou a "O Cacto" (cf. D. Arrigucci, 1997, pp. 17-76) poderão estranhar o destaque da afetividade como traço constitutivo da protoforma bandeiriana. "Belo, áspero, intratável" é tanto o cacto referencial, como o poema em que o cacto se transforma. Embora seu tratamento seja excepcional na obra de Bandeira - Murilo Mendes, no "Murilograma" que lhe dedicava, o designava "Anticacto és" -, seu exemplo é lembrado para que se reitere que uma protoforma não é algo fixo e invariante, senão que um conjunto hierarquizado de marcas ou traços. Ora, a aspereza de "O Cacto" não afeta seu tratamento do tempo - no máximo, seria possível dizer-se, a partir da comparação da planta com o "Laacoonte", que o poema estende até o presente a atrocidade, comum aos diversos tempos, da vida. E isso significa que o presente evacuado é seu traço mínimo.

Antes de passarmos à transformação que esse esquema receberá em João Cabral, será oportuno verificar-se o choque que a poesia deste outro pernambucano causará. Testemunho evidente desse choque é fornecido por um crítico que, desde o começo, soube reconhecer que algo ali soava diferente. Refiro-me a Sérgio Buarque de Holanda. Em artigo de agosto de 1952, dizia ele: "Confesso bastante envergonhado que meus primeiros contatos com sua obra e, depois, o crescente interesse que ela pôde inspirar-me, nem sempre me deixaram totalmente livre de hesitações ou suspeitas" (S. B. Holanda, 1952, p. 516). Na verdade, o crítico não tinha razão em se envergonhar de suas hesitações. Acompanhando suas diversas alusões ao poeta e a seus companheiros de geração, verifica-se que Sérgio Buarque compreendera com nitidez o que os separava. Assim, indispondo-se contra a opinião que deveria ser corrente naqueles anos, observava nada ser mais falso do que se falar a propósito de Cabral em formalismo (p. 520). E, contudo, era explicável que o choque causado ainda o fizesse manter certas hesitações. É assim que, ante passagem da Psicologia da Composição"[...] a forma atingida / como a ponta do novelo / que a atenção, lenta, / desenrola, aranha [...]" - , Sérgio Buarque se perguntava: "Até onde nos levará essa valorização do artesanato pelo artesanato [...]?" (p. 521). Participava do mesmo equívoco dúvida anteriormente expressa: “[...] A luta do poeta pela expressão nítida, cristalina, que vai aos extremos de uma linguagem crítica, já não parece traduzir [a] aspiração de um mundo sereno, povoado de essências puras que prolonga, requintando-o apenas, o próprio ideal de beleza herdado do renascimentoe do petrarquismo?" (p. 520). Tais hesitações não impediam que Sérgio Buarque compreendesse o fio da meada em que se depositava a composição cabralina: "O que parecia traduzir-se naquele zelo sempre atento não era apenas uma poética, na acepção mais corrente e usual do vocábulo. Era mais, e principalmente, uma espécie de norma de ação e de vida. A estética, em outras palavras, assentava sobre uma ética" (p. 517, grifos meus).

As passagens transcritas mostram claramente o que representou para um crítico de qualidade o início da produção cabralina. Seria hoje mesquinho criticá-lo por suas dúvidas, quando não só soubera distinguir Cabral da tradição luso-brasileira, do modernismo e de seus companheiros da geração de 45, como perceber que sua produção supunha "uma norma de ação e vida", pela qual a estética se enraizava em uma 
ética. Essa última observação, de fato, serve de abertura para a compreensão da protoforma cabralina.

A exemplo do que fizemos com Bandeira, procuraremos concretizá-la pelo exame de um poema, "O Vento no Canavial" (em Paisagens com Figuras, publicado em Duas Águas, 1956).

"Não se vê no canavial nenhuma planta com nome, nenhuma planta maria, planta com nome de homem.

É anônimo o canavial, Sem feições, como a campina; É como um mar sem navios, papel em branco de escrita.

É como um grande lençol sem dobras e sem bainha; penugem de moça ao sol, roupa lavada estendida.

Contudo há no canavial oculta fisionomia: como em pulso de relógio há possível melodia,

ou como de um avião a paisagem se organiza, ou há finos desenhos nas pedras da praça vazia.

Se venta no canavial estendido sob o sol seu tecido inanimado faz-se sensível lençol,

se muda em bandeira viva, de cor verde sobre verde, com estrelas verdes que no verde nascem, se perdem.

Não lembra o canavial então, as praças vazias: não tem, como têm as pedras, disciplina de milícias.

É solta sua simetria: como a das ondas na areia ou as ondas da multidão lutando na praça cheia.

Então, é da praça cheia que o canavial é a imagem: vêem-se as mesmas correntes que se fazem e desfazem,

voragens que se desatam, redemoinhos iguais, estrelas iguais àquelas que o povo na praça faz".

Salvo o primeiro verso das estrofes $1 \mathrm{e}$ 2, octossilábico, as onze estrofes se organizam em setissílabos. Os verbos estão todos no indicativo presente. Porém, à diferença de Bandeira, não há oposição entre presente gramatical e presente referencial. Muito ao contrário, um é o outro. Mas a diferença apenas começa. À coincidência entre os aspectos gramatical e referencial do presente corresponde um dinamismo que se modifica a cada grupo de estrofes. Não um dinamismo que resultasse do relato de uma história mas o que se constitui pelo desdobramento interno do título-lema: o vento no canavial. À diferença no tratamento do tempo se ajunta uma semelhança: como já em Bandeira, não há pessoalização, não há psicologia. Ela no entanto se acompanha doutra diferença: a impessoalização não é substituída pela afetividade envolvente. A emotividade do leitor só será despertada se ele contar com sua sensibilidade intelectual. E a presença humana dependerá do trabalho sobre o lema, tendo por núcleos o trabalho verbal sobre uma única imagem condutora: a planta cana. Como se cumpre esse trabalho imagético? Como essa renúncia da afetividade em um poema de simetria métrica quase absoluta não converte o texto em uma peça fria, estática, neoparnasiana? Tudo dependerá da dinâmica que o move. Em vez de estatuária, o canavial forma, a exemplo de Calder, um verdadeiro mobile. O mobile se inicia com a dessingularização do objeto: "Não se vê no canavial / nenhuma planta com nome / nenhuma planta maria". Por outro lado, a variante das rimas - desde a ausência de 
rimas, passando pelas rimas toantes ("nome - homem"; “campina-escrita”), até a perfeita homofonia - cria a ambiência para a dinâmica a ser processada. Assim, afirmada a impessoalidade de início, a máquina do poema começa por alargar seu campo visual: o canavial "é como um mar sem navios, / papel em branco de escrita”. E o campo visual continua a se alargar: “É como um grande lençol / penugem de moça ao sol / roupa lavada estendida". A extensão do visualizado por si só, entretanto, ameaçaria fazer o poema sossobrar no estático. Trata-se de rever o campo desdobrado, em que o canavial contém o mar que, sem navios, é comparável a uma presença feminina sem eros - "penugem de moça ao sol" e compreender que tudo aquilo se deposita sobre outra camada. É o que declara a quarta estrofe: “Contudo há no canavial / oculta fisionomia: / como em pulso de relógio / há possível melodia”. Como, entretanto, poder-se-á dizer que a oculta fisionomia é vista? Como ver a possível melodia? Não faz sentido falar-se em ver ou outro qualquer sentido. Assim como a cena material - o canavial - se ampliara noutras cenas que, embora materiais, não são, em seu conjunto, materiais, pois apreendidas e dependentes tão-só da estruturação verbal, assim também "ver" se desdobra noutra dimensão, não confundida com um órgão dos sentidos. A essa outra dimensão chamamos visualização. Uma análise mais demorada mostraria que a visualização é resultante da plasticidade que Cabral dizia haver aprendido com Murilo Mendes. Aqui no entanto basta assinalar que visualização, na poesia cabralina, significa o ultrapasse da oposição clássica entre campo dos percepta e intervenção da imaginação. O visualizável atualiza o que está sob o que se vê; radiografia passível de ser processada apenas pela palavra ou, no pintor, pelo pincel. Contudo, para que o que está sob não se espiritualize, isto é, para que não dependa da tematização do imaginário que abandona o campo perceptual, será preciso que o poeta não supervalorize a imagem gerada. Daí as alternativas que se reiteram na quinta es- trofe: a oculta fisionomia é a que há na melodia possível em pulso de relógio ou como a paisagem se organiza de um avião $o u$ como os desenhos que traçam as pedras da praça vazia.

Aos dois movimentos até agora reconhecidos - o movimento de ampliação do canavial e sua escavação interna - agora um terceiro se acrescenta: o vento no canavial. Até então as plantas sem nome guardavam sua possível melodia. Ao agitá-las, o vento criará desenhos diversos. Desde logo, "seu tecido inanimado / faz-se sensível lençol”. Já não é lençol sem dobras mas sim que se anima e então converte em bandeira - não alegórica, porém viva e aleatória. Isso, pois, como declara o verso: "É solta sua simetria”. O que, de sua parte, permite um outro alargamento imagético: “como a das ondas na areia / ou as ondas da multidão / lutando na praça cheia”. A figura humana que reaparece se integra, sem privilégios privados, ao mundo. $O$ coletivo vegetal se transforma no coletivo humano da praça cheia, por sua vez comparável ao coletivo mineral e líquido da areia e das ondas marinhas. Mas as duas comparações - a das ondas na areia ou as da multidão na praça - não têm o mesmo peso. As duas estrofes finais intensificam ao máximo o campo da visualização - correntes que se fazem e desfazem, voragens que se desatam, redemoinhos.

A leitura que acabamos de fazer é apenas a que segue a ordem da leitura. Numa releitura, veríamos como a composição, depois de configurar seu campo, retrabalha seus elementos e os desdobra em sua intensidade aleatória. Porque aleatória, a intensidade não dispõe de um clímax, acorde final de um relato. A planta sem nome, pertencente a um coletivo vegetal, mostra conter dentro de si voragens, redemoinhos, "estrelas iguais àquelas / que o povo na praça faz".

Não escolhemos este poema senão de maneira também aleatória. Embora fosse absurdo pensar-se que houvéssemos captado a fórmula poemática de Cabral (!), podemos supor que "O Vento no Canavial" torna palpável a protoforma de sua "psico- 
logia da composição". Caso estejamos certos, ela se opõe ao modelo bandeiriano de imediato pela ocupação, completamente diversa, do tempo. O presente, em vez de esvaziado em função de uma cena meditativa do passado, é intensificado tanto no sentido horizontal - os percepta formam um conjunto não apreensível como percepta, o que os reduziria a um poema realista - como no sentido vertical - há no canavial possível melodia, que, entretanto, não tem a regularidade de uma peça cantabile, pois é solta sua simetria. Presente intensificado que, como já dissera Sérgio Buarque de Holanda, supõe uma estética assentada em uma ética, sem entretan- to recair, como ainda temia seu excelente leitor, na "aspiração de um mundo sereno, povoado de essências puras”. Esta ética, mesmo porque enraizada no presente, é uma ética da pólis, ao passo que a bandeiriana, oriunda de um passado afetivizado, é uma ética da fraternidade.

Proponente de uma ética da pólis, não há em Cabral essências, muito menos puras, ou aspiração de um mundo sereno, não há envolvimento imediato do leitor, mas sim a sua instigação para um alerta sensível e pensado para os jogos sem conta do mundo. Estes não se dão ao lado ou fora do poema, pois os jogos do mundo, como diria o filósofo, são jogos da linguagem.

\section{REFERÊNCIAS BIBLIOGRÁFICAS}

ANDRADE, M. "A Poesia em 1930", (1931), republicado in: Aspectos da Literatura Brasileira. São Paulo, Livraria Martins, 1943.

ARRIGUCCI JR., D. "Beleza Humilde e Áspera", in O Cacto e as Ruína. São Paulo, Duas Cidades, 1997.

BANDEIRA, M. "La Poésie de Blaise Cendrars et les Poètes Brésiliens", in Journal Français du Brésil "Présences

Françaises au Brésil", Édition Spéciale hors série, cinquième anniversaire, 11 de julho de 1957.

BLOCH, E. "Ungleichzeitigkeit und Pflicht zu ihrer Dialektik", in Erbschaft dieser Zeit (1935). Frankfurt a.M., Suhrkamp, 1985, pp. 104-60.

HOLANDA, S. B. "João Cabral de Melo Neto" (3 de agosto de 1952), republicado in: A. Arnoni Prado (ed.), 0

Espírito e a Letra. Estudos de Crítica Literária, vol. II (1948-1959). São Paulo, Companhia das Letras, 1996, pp. 516-21. 